\title{
Bir Edebiyat Festivali Modeli: Read My World 2018*
}

\section{Süreyyya Evren**}

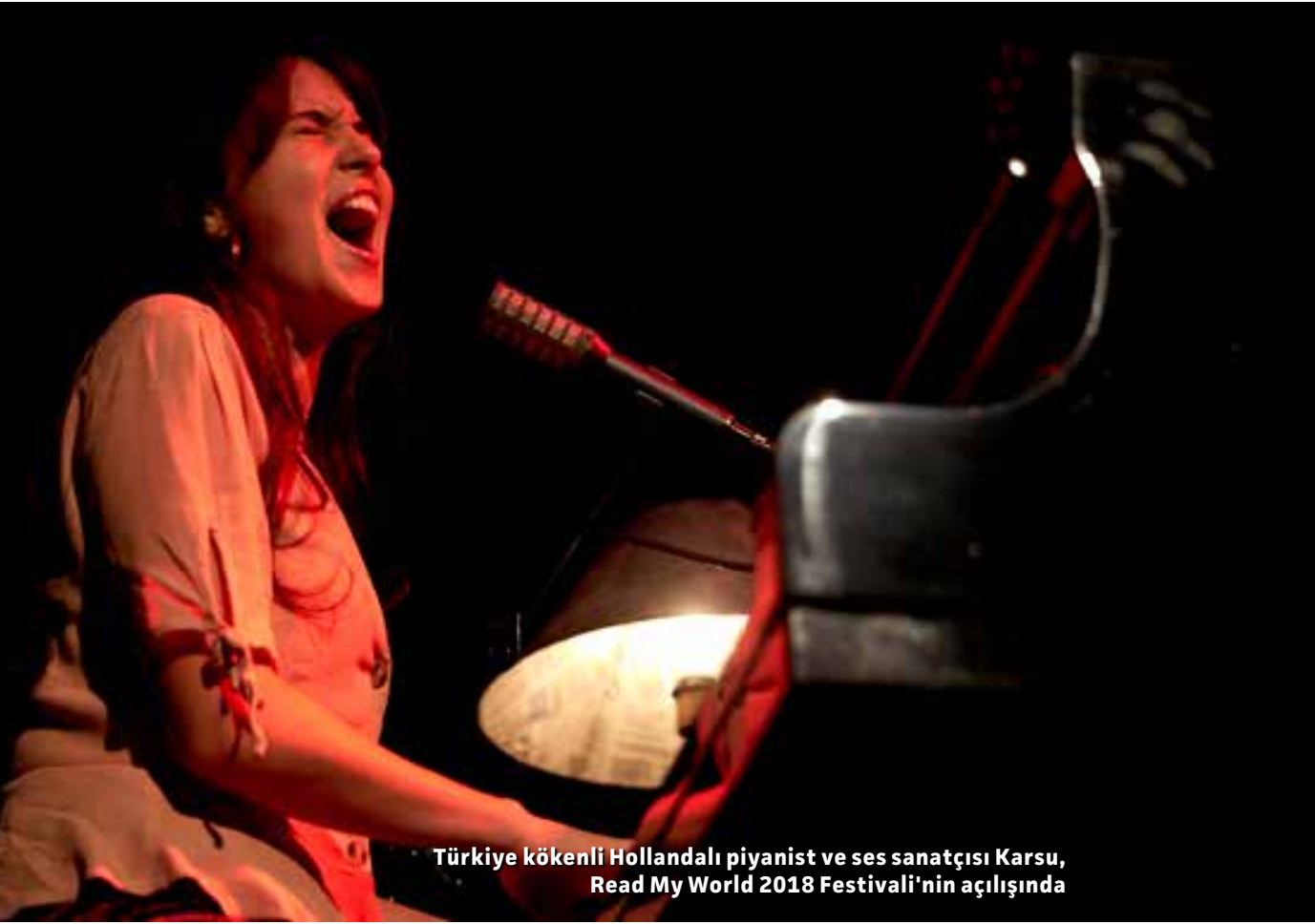

Amsterdam'da düzenlenen esnek bir edebiyat festivalleri dizisi Read My World. Edebiyat festivali ama diğer disiplinlerle de sürekli temas halinde; ülke temsiline odaklıymış gibi görünüyor ama bu temsilin sınırlarını kolayca gevşetiyor.

Illk edisyonu 2013’te, Arap Devrimleri'nden kısa bir süre sonra, Türkiye'de Gezi yaşanırken Filistin ve Mısır'ı merkeze alarak Arap edebiyatına yoğunlaşmış. 2014'te Karayipler'i; 2015'te Endonezya, Malezya ve Singapur etrafında Güneydoğu Asya'yı; 2016'da Ukrayna ve Polonya'yı; 2017'de de Siyahî ABD’yi gündemine almış.

Read My World’ün Türkiye üzerinde duran ve 11-13 Ekim 2018 tarihleri arasında Amsterdam'da gerçekleşen altıncı edisyonunun küratörlüğünü Aylime Aslı Demir ile birlikte üstlendik. Etkinliğin yapısı ile ilgili de bir fikir veriyor aslında Amsterdam'da düzenlenen bir etkinliğin Türkiyeli iki küratörü olması. Read My World ekibi ilk olarak odaklanacağı bölge veya dilden biri kadın biri erkek olmak üzere iki küratör belirlemek için söz konusu bölgede çok sayıda kültür insanıyla görüşme yaparak çalışmalarına başlıyor. Festival ekibinden Willemijn Lamp ve Marije Koens, ilk görüşmemizde bana bu yordamın gerekçelerini anlatırken önyargılardan, klişelerden, olağan

* Read My World, Amsterdam'ın edebiyat ile gazetecilik arasındaki sınırları araştıran uluslararası edebiyat festivalidir. Festival altıncı yılında Türkiye'deki edebiyat ve sanat alanlarının yüzlerini ve seslerini bir araya getirdi. Ayrıntılı bilgi için bkz. http://www.readmyworld.nl. Fotoğraflar: Richard Tas.

** Arter 
şüphelilerin çağrıdığı festivaller düzenlemekten bu şekilde sıyrılabileceklerini hesapladıklarını anlatmışlardı. Read My World geleneğinde, içeriden küratörler içeriden dertlere, hassasiyetlere, eğilimlere duyarlı bir perspektifin festivalin o yılki doğasını belirlemesine aracıllık ediyor. Böylece Hollanda kültür çevreleri Hollanda'da Türkiye hakkında veya Türkiye edebiyatı hakkında bir festival düzenliyor gibi olmuyor da Hollandalıların önayak olduğu Türkiye ve edebiyatı odaklı bir festival, Türkiyeli yazar çizerlerin ve Hollandalı edebiyat ve kültür insanlarının katıımıyla birlikte düzenlenebiliyor sözgelimi. Bizim edisyonun örneğinde, Türkiye kökenli Hollandalıların da festivalde ciddi bir ağırı̆̆ı oldu diyebiliriz.

Read My World ulus temsillerini yeniden üreten, ezbere bir bakışla değil o ülkenin kültürel ikliminin kendi temsiline dair problemleri kendisinin ele alabileceği ve mümkün olduğunda bunların üstesinden gelebileceği bir platform yaratmaya niyetli bir festival olarak karşımıza çıktı. Türkiyeli küratörlerle beraber çalışan ve Canan Maraşlıgil, Lisanne Snelders, Zola Can ve Maya Shamir'den oluşan bir de Hollandalı "editörler" ekibinin varlığını belirtmek gerek. Festivalin biçimi bazı sınırlar da belirlemişti. Türkiyeli küratörler toplam 16 isim önereceklerdi. Ve sonra Hollanda'da editörlerle bir araya geldiler. Orada Türkiye'den önerilen isimlere Hollanda'dan karşılıklar hayal edildi; olası paneller, atölyeler, etkinlikler için kimlerin kimlerle nasıl eşleştirilebileceği düşünüldü. Toplumsal cinsiyet eşitliğinden tür dağılımına kadar çeşitli dengeler de gözetilerek 16 kişilik liste sekiz kişiye indirildi. Türkiye'den Amsterdam'a davet edilecek yazarlar belli olmuştu: Enis Akın, Sevinç Çalhanoğlu, Karin Karakaşısı, Sema Kaygusuz, Cem Sorguç, Seray Şahiner, Ali Duran Topuz ve Murat Uyurkulak'ın katılımı şiirin, öykünün, romanın temsillerine gazeteciliğin, radyoculuğun, mimarlığın temsillerini de ekleyen bir kültürel hikâye gözetti.

Read My World 9 Ekim 2018'de Belçika'nın Brüksel şehrinde, Bozar'da gerçekleşen bir panelle başladı ve 2013'ten bugüne KAOS GL dergisinin editörlüğünü yürüten yazar ve küratör Aylime Ası Demir ile Türkiye edebiyatının önde gelen iki ismi, Sema Kaygusuz ve Karin Karakaşlı, yazar ve çevirmen Canan Maraşlıgil'in moderatörlüğünde zor zamanlarda yazmanın hallerini konuştular.

Festivalin Amsterdam'daki açılışı, 11 Ekim akşamı, Tolhuistuin Kültür Merkezi'nde Türkiye kökenli Hollandalı müzisyen Karsu'nun şarkıları eşliğinde gerçekleşti. Açılış gecesinde Türkiyeli yazarlardan kendilerini kendi seçtikleri biçimlerde kısaca tanıtmaları istenmişti. Slaytlar gösteren de oldu, metinler de okundu, Rebetiko şarkılar da dinletildi. Açılışta küratörler olarak katıldığımız

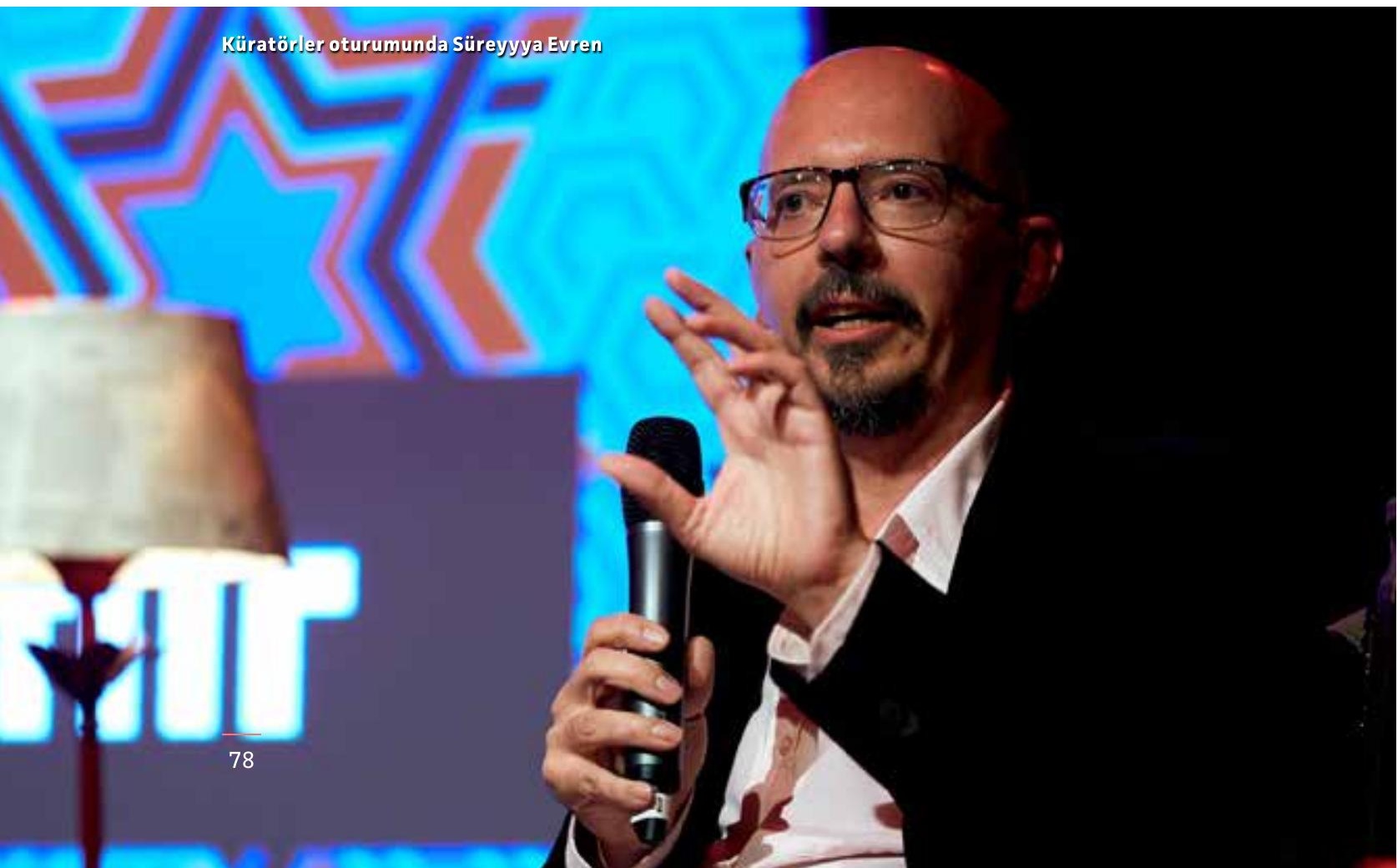


Ardından festival Türkiye edebiyatını Türkiye'nin hikâyelerinin büyük çeşitliliği içinde ele almaya dönük yoğun programıyla sürdü: Şairler liseli gençlerle şiir okulundan açık havada deneysel şiir okuma gecelerine türlü etkinlikler düzenlediler. 1970'lerden bugüne Türk dizilerinin tüm dünyada izleyicilerin hayatına etkisi küresel bir bağlamda iki panelle ve bir belgesel eşliğinde tartışıldı. Flanörler kadar flanözlerin de öne çıkarıldığı kent yürüyüşleri, Amsterdam'daki nezihleştirme ve kentsel dönüşüm hamleleriyle İstanbul'un karşılaştırılması, mimariden yazına İstanbul'un mekânları ve yapıları, Türkçenin istisnai halleri ve yapay zekânın yanıtları, Koçgiri Kürtçesinde öyküler, LGBTiQ+ hakları ve queer stratejiler birbirini izledi. Her iki ülkeden gazeteciler ana akım medyanın güvenilirliğini yitirmesi esnasında ortaya çıkan alternatif medyanın gazetecilik anlamında önemini, marjinalleştirilmiş seslere medyada nasıl yer verilebileceğini ve araştırmacı gazeteciliğin popülizm dönemindeki rolünü konuştular. Çeviri atölyeleri ve özel DJ setleri katılımcıları ağırladı. Edebiyatçılar yazmaya başladıkları dönemlerde beslendikleri kültürel köklerine birlikte döndüler. Dünyadan çeşitli devrim meydanları devrimci ân geçtikten sonra edebiyatın sürdürdüğü mücadelelere de bakarak irdelendi. Sulukule, Zeki Müren, KHK ile atılan hocaların İstanbul'da açtığı rock barlar hakkında filmler, videolar gösterildi. Ve festival 13 Ekim gecesi kamp ateşi etrafında müzik, şiir ve hikâyelerin okunmasıyla kapandı.

Genel bir değerlendirme yapacak olursak edebiyata bakmayı ülkenin hikâyelerine, ev sahibi ülkenin hikâyeleriyle bağlantılara da izin verecek şekilde bakmanın bir kanalı olarak yorumlamanın gayet iyi iş gördüğünü söyleyebiliriz.

Sözgelimi SG Reigersbos, Open Schoolgemeenschap Bijlmer, Fons Vitae Lyceum ve Montessori Lyceum Amsterdam'dan gelen öğrenciler, School der Poëzie'nin (Şiir Okulu) öğretmenleri ile şiir derslerine katıldılar ve festival için Türkiye'den gelen şairlerin eserlerinden esinlenerek kendi şiirlerini yazdılar. İki butik kitabevinin festivalin düzenlendiği Tolhuistuin Kültür Merkezi'nin fuayesine açtığı standlarda Hollandacaya çevrilen Türkiye edebiyatı örnekleri sergilendi. Özellikle İstanbul ve Amsterdam'ı abluka altına alan kentsel dönüşüm hamlelerini karşılaştıran, sert yıkım ve aldırışsız inşa uygulamalarını kültür üzerinden kat ettiği kadar sokakta da arayan etkinlikler düzenlendi. Festival katılımcılarının öncülük ettiği flanözler yürüyüşü katılımcıları kültür merkezinden çıkarıp Kuzey Amsterdam sokaklarına, Amsterdam'ın en hızlı değişen bölgelerine attı.

Feminist yayınevi Chaos'tan Yael van der Wouden ile KAOS GL'den Aylime Aslı Demir 


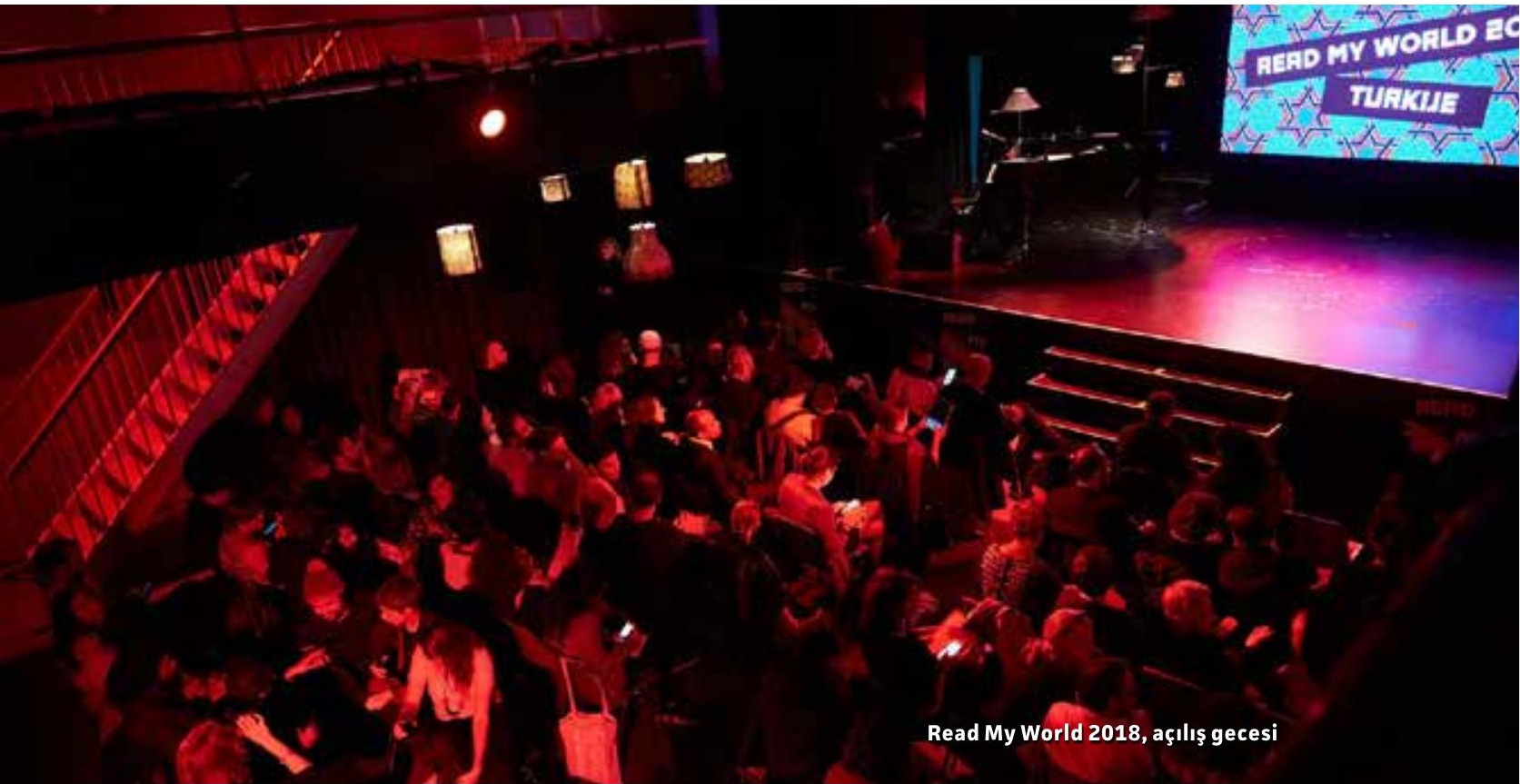

Sema Kaygusuz'un bir öyküsünden uyarlanan, oyunculuklarını Serkan Keskin ile Serdar Orçin'in yaptığı Kerem Ayan'ın kısa filmi Kılçık (2015), Burak Delier'in Barış Akademisyenleri'ni ve işinden olan gazetecileri konu edinen Bardergi: Kendini Bar Zanneden Dergi (2018) adlı videosu, Nina Maria Paschalidou'nun Türk dizilerinin dünyadaki popülaritesini inceleyen belgeseli KIsmet (2013), Beyza Boyacıoğlu ile Jeff Soyk'un Zeki Müren fenomenini ele aldıkları Zeki Müren Yardım Hattı (2016), Azra Deniz Okyay'ın belgeseli Sulukule Mon Amour (2016) seçilen filmlerin de ne denli geniş bir Türkiye manzarasına talip olduklarını anlatıyor gibiydi.

Bir Türkiyeli yazar ile bir Hollandalı yazarın, Batı edebiyat dünyasında Türk yazarı imgesine odaklanan ve festival öncesinde ilerlettikleri yazışmalarına dayanan "iç̧en Bir Yaklaşım" başııkı oturumlar başka zamanları, başka yerleri ve mektubun sağladığı iletişim dilini panellerin arasında diri tutan özel ânlardı. Bu vesileyle şunu da söylemek gerekir ki festival pek çok yeni içeriğin, yeni metnin üretilmesine de etkinliklerin yapısı dolayısıly vesile oldu.

Buna festival öncesinde Hollandalı gazeteci Raşit Elibol ile Gazete Duvar'ın kurucusu ve editörü, Türkiyeli gazeteci Ali Duran Topuz arasında bir diyalog eklendiğinde “ifade özgürlüğü”nün farkı bağlamlarda anlamlarını araştırmanın da bir sahnesi kurulmuş oldu. Türkiye'de de tanınan Hollandalı gazeteci Fréderike Geerdink'in katıldığı bir başka panel basın özgürlüğü ve toplumsal kutuplaşma sorunlarını masaya yatırdı. Ve etkinliklerin hep akşam saatlerinde düzenlendiğini, böylesi bir kaşları çatık basın özgürlüğü panelinden çıkısta Rotterdam'dan çıkan ve kulüp geceleri organize ederek Türk müziğinin mirasını izleyen yerel bir DJ kolektifi olan Anadolu Ekspres'in müziğinde kendini bulmanın mümkün olduğunu da not edelim. Doğrudan edebiyat meselelerinin hissedildiği Şiir Çeviri Atölyesi gibi atölyeler, iki ülkeden yazarların çocukluklarında beslendikleri öğeleri anlattıkları ve kültürel köklerini karşılaşıırdıkları panellerle, Türkçedeki hüzün sözcüğünü devasa bir projeye evrilterek didik didik etmeye koyulmuş Nihat Karataşlı ve Inez Piso ikilisiyle sürdü.

Read My World bir karşılaşma ânı hayal ediyor tüm örgütlenmesiyle. Kültürlerarası, yazarlararası, okurlararası, disiplinlerarası bir çoklu karşılaşma ânı. Ve bunu olabildiğince kolay yollardan yapmamaya; kolay akan, zorlamayan, esnek, ama yeni yollardan gerçekleştirmeye çalışıyor.

Bizim deneyimimiz, bu hedeflerin büyük ölçüde başarılabilir kılındığı bir biçimin geliştirildiğini düşünmemizle sonuçlandı. 